\title{
What autoantibody tests should become widely available to help scleroderma diagnosis and management?
}

\author{
Yoshinao Muro*, Kazumitsu Sugiura and Masashi Akiyama \\ See related research by Mahler et al., http://arthritis-research.com/content/15/2/R50
}

\begin{abstract}
Anti-Th/To autoantibodies have been recognized as serological markers of systemic sclerosis (SSC) for more than 20 years. However, validated immunoassay kits to test this specificity have not been commercially available. SSc autoantibodies are basically mutually exclusive and are associated with a certain subset of the disease and/or with organ involvement. Anti-Th/ To are generally considered to be markers of the limited cutaneous type of SSc with the involvement of certain internal organs. The excellent correlation between anti-Rpp25 as detected by their novel chemiluminescent method and anti-Th/To as detected by immunoprecipitation suggest that the new assays may become widely available tests for clinicians in future and could help to clarify the clinical significance of anti-Th/To in SSc as well as other conditions over different races or countries.
\end{abstract}

In a previous issue of Arthritis Research $\mathcal{E}$ Therapy, Mahler and colleagues reported a novel immunoassay for detecting anti-Th/To autoantibodies [1], which has the potential to make this testing widely available to clinicians using the newly developed ELISA and chemiluminescent immunoassay (CLIA). Serum from patients with systemic autoimmune rheumatic diseases often contains clinically important autoantibodies that react with various intracellular antigens. Detection of anti-nuclear antibodies by indirect immunofluorescence is widely accepted as a screening test for the diagnosis of many systemic autoimmune rheumatic diseases.

*Correspondence: ymuro@med.nagoya-u.ac.jp

Division of Connective Tissue Disease and Autoimmunity, Department of

Dermatology, Nagoya University Graduate School of Medicine, 65 Tsurumai-cho, Showa-ku, Nagoya 466-8550, Japan
Systemic sclerosis $(\mathrm{SSc})$ is a disease characterized by collagen deposition and subsequent fibrosis in skin and internal organs. The extent of fibrosis shows considerable variation in severity, which classifies SSc into two distinct subtypes: the limited cutaneous form and the diffuse cutaneous form. Among SSc-associated autoantibodies, anti-centromere antibodies are widely accepted to be associated with limited cutaneous SSc while anti-topoisomerase I and anti-RNA polymerase III (anti-RNAP) antibodies are associated with diffuse cutaneous SSc [2]. In contrast to these three specific antibodies that have been widely used in the diagnosis and management of SSc patients, SSc autoantibodies showing nucleolar immunofluorescence staining pattern have not been utilized. There are two kinds of anti-nucleolar antibodies (ANoA): anti-U3-RNP (fibrillarin) and anti-Th/To [3]. Although they are mainly found in patients with SSc, information on their clinical significances is limited and inconclusive, partly due to a lack of commercially available antibody tests.

Mahler and colleagues detected anti-Th/To antibodies using recombinant Rpp25, which is a component of the more than 10 proteins in the Th/To RNA-protein complex [4]. They utilized full-length, purified, recombinant human Rpp25 antigen for the quantitative measurement of anti-Th/To antibodies, which were defined by immunoprecipitation as the reference method. The newly established CLIA showed high sensitivity $(100.0 \%=8 / 8)$ and specificity $(99.5 \%=365 / 367)$ comparable with or better than ELISA. In another cohort, an ELISA indicated three cases showing false-negative anti-Th/To detection, which may be resolved by adding other antigenic components to the coated antigens. In CLIA, two false-positive cases were found, which were ANoA-negative. Evaluation with simultaneous performing anti-nuclear antibodies by indirect immunofluorescence is still important.

The coexistence of SSc-marker antibodies in the same patient is rare. ANoA-positive SSc or SScsuspected patients, who do not have anti-centromere, 
anti-topoisomerase I, or anti-RNAP antibodies, will be a subset with high probability of having anti-Th/To or antiU3-RNP antibodies. Anti-Th/To antibodies are frequently found in limited cutaneous SSc patients, often those with interstitial lung disease and pulmonary hypertension $[2,5]$, whereas anti-U3-RNP antibodies are associated with pulmonary hypertension, renal disease and myositis in diffuse cutaneous SSc patients [2]. The prevalence of these antibodies in patients with SSc varies for different ethnic backgrounds. For example, in the US SSc cohort, all African-American patients with ANoA-dominant antibodies had anti-U3-RNP, which was found in 30\% of all patients, whereas anti-Th/To was found in only $3 \%$ [6]. In Caucasian patients, however, anti-Th/To was more frequently found than anti-U3-RNP (9\% vs. 4\%). In Italian patients, anti-Th/To was found in $4 \%$ whereas anti-U3RNP was not found [6]. These antibodies were detected by complicated RNA analysis using immunoprecipitation and silver staining of RNAs or a radioisotope-based immunoprecipitation assay.

Some autoantibodies have great diversity in their prevalence among different races and countries, besides the above instances. Recent studies showed that the prevalence of anti-RNAP antibodies was lower in French patients than in the US patients [7]. Anti-Mi-2 antibodies, which are first described as a serological marker of dermatomyositis, were the most common in patients with adult-onset dermatomyositis in Mexico City (59\%) [8]. This finding is surprising to us because only $5 \%$ of Japanese dermatomyositis patients had anti-Mi-2 antibodies in our study [9]. Commercially available immunoassay kits would make it easier to perform international studies. Since immunoassays using CLIA have very high sensitivity (for example, chemiluminescent ELISA [10]) and are time-saving (for example, beads assay in a liquid phase [1]), the development of such assays would be a reasonable direction for autoantibody immunoassays.

SSc specificity and the clinical association of antiRNAP antibodies have been known for over 20 years; however, until recently, the detection of these antibodies had been utilized only at a few institutions that can perform radioimmunoprecipitation. Since the antiRNAP ELISA kit became widely available to clinicians, it has now become a part of routine serological tests in SSc. More and more data from different countries have become available, which have illustrated the difference in prevalence and clinical association of anti-RNAP antibodies. Anti-Th/To immunoassay may become utilized in a similar way in future. The newly established method for measuring autoantibodies should be carefully evaluated using large international cohorts of SSc patients and other autoimmune conditions, to establish its utility and clinical significance. In SSc clinics, it will be ideal to have reliable, commercially available immunoassays for major ANoA, anti-Th/To antibodies and anti-U3-RNP antibodies, in addition to anti-PM-Scl antibodies, which are a marker of polymyositis/scleroderma overlap syndrome [1].

\section{Abbreviations}

ANoA, anti-nucleolar antibodies; CLIA, chemiluminescent immunoassay; ELISA, enzyme-linked immunosorbent assay; RNAP, RNA polymerase III; SSC, systemic sclerosis.

\section{Competing interests}

The authors declare that they have no competing interests.

Published: 8 July 2013

\section{References}

1. Mahler M, Gascon C, Patel S, Ceribelli A, Fritzler MJ, Swart A, Chan EKL, Satoh M: Rpp25 is a major target of autoantibodies to the Th/To complex as measured by a novel chemiluminescent assay. Arthritis Res Ther 2013, $15: R 50$.

2. Steen VD: Autoantibodies in systemic sclerosis. Semin Arthritis Rheum 2005, 35:35-42.

3. Satoh M, Vazquez-Del Mercardo M, Chan EKL: Clinical interpretation of antinuclear antibody tests in systemic rheumatic diseases. Mod Rheumatol 2009, 19:219-228.

4. Van Eenennaam $\mathrm{H}$, Vogelzangs $\mathrm{JH}$, Lugtenberg $\mathrm{D}$, Van Den Hoogen $\mathrm{FH}$, Van Venrooij WJ, Pruijn GJ: Identity of the RNase MRP-and RNase P-associated Th/To autoantigen. Arthritis Rheum 2002, 46:3266-3772.

5. Ceribelli A, Cavazzana I, Franceschini F, Airo P, Tincani A, Cattaneo R, Pauley BA, Chan EK, Satoh M: Anti-Th/To are common antinucleolar autoantibodies in Italian patients with scleroderma. J Rheumato/ 2010, 37:2071-2075.

6. Krzyszczak ME, Li Y, Ross SJ, Ceribelli A, Chan EK, Bubb MR, Sobel ES, Reeves WH, Satoh M: Gender and ethnicity differences in the prevalence of scleroderma-related autoantibodies. Clin Rheumatol 2011, 30:1333-1339.

7. Meyer O, De Chaisemartin L, Nicaise-Roland P, Cabane J, Tubach F, Dieude P, Hayem G, Palazzo E, Chollet-Martin S, Kahan A, Allanore Y: Anti-RNA polymerase III antibody prevalence and associated clinical manifestations in a large series of French patients with systemic sclerosis: a crosssectional study. J Rheumatol 2010, 37:125-130.

8. Petri MH, Satoh M, Martin-Marquez BT, Vargas-Ramirez R, Jara LJ, Saavedra MA, Cruz-Gonzalez C, Andrade-Ortega L, Vera-Lastra OL, Salazar-Paramo M, Prieto-Parra RE, Gonzalez-Lopez L, Gamez-Nava Jl, Ramirez-Sanches HU, Chan JY, Ross SJ, Chan EK, Vazquez-Del Mercado M: Implications in the difference of anti-Mi-2 and -p155/140 autoantibody prevalence in two dermatomyositis cohorts from Mexico City and Guadalajara. Arthritis Res Ther 2013, 15:R48.

9. Muro Y, Ishikawa A, Sugiura K, Akiyama M: Clinical features of anti-TIF1-a antibody-positive dermatomyositis patients are closely associated with coexistent dermatomyositis-specific autoantibodies and anti-TIF1- $\gamma$ or anti-Mi-2 autoantibodies. Rheumatology (Oxford) 2012, 51:1508-1513.

10. Ishikawa A, Muro Y, Sugiura K, Akiyama M: Development of an ELISA for detection of autoantibodies to nuclear matrix protein 2. Rheumatology (Oxford) 2012, 51:1181-1187.

doi:10.1186/ar4241

Cite this article as: Muro $Y$, et al:: What autoantibody tests should become widely available to help scleroderma diagnosis and management? Arthritis Research \& Therapy 2013, 15:116. 